\section{NOD2 regulation of Toll-like receptor responses and the pathogenesis of Crohn's disease}

\author{
T Watanabe, A Kitani, W Strober
}

NOD2 signalling can both positively and negatively regulate Tolllike receptor (TLR) responses. Previous studies have shown that lack of NOD2 signalling (in NOD2 knockout mice) leads to increased peptidoglycan induction of interleukin (IL)-12 via TLR2. Studies in this issue of Gut show that lack of NOD2 signalling (in patients with NOD2 mutations) leads to decreased CpG induction of tumour necrosis factor and IL-8 via TLR9. The first type of abnormality suggests that NOD2 mutations act by enhancing effector T cell function and the second that NOD2 mutations act by impairing regulatory $\mathrm{T}$ cell function. We weigh these possibilities.

$\mathrm{S}$ everal years ago it was discovered that homozygous (or compound heterozygous) mutations of CARD15, a gene encoding NOD2 (nucleotide oligomerisation domain 2), are a major susceptibility factor underlying a significant subgroup of patients with Crohn's disease in Western countries. ${ }^{1-4}$ More recently it has been shown that mutations of this gene are also associated with diseases that are immunologically related to Crohn's disease, such as early onset sarcoidosis. ${ }^{5}$ Thus it has become increasingly clear that these mutations offer an extraordinary window on the function of the mucosal immune system and how defects in such function lead to disease.

The road to understanding the consequences of NOD2 mutations begins with knowledge of how NOD2 functions in normal individuals. NOD2 is now known to be a member of a large and somewhat heterogeneous protein family known as the NOD-LRR (leucine-rich repeat) protein family that are grouped together because they more or less share the same structural regions: an LRR domain, a NOD domain, and a CARD (caspase recruitment domain) (as in the case of NOD2) or PYRIN domain. ${ }^{6}$ The LRR domain is a cognate of a similar domain found in all members of the Toll-like receptor (TLR) family and that is used by such TLRs to recognise an array of microbial components. It is in fact through such recognition that TLRs facilitate "innate" (rapid and non-specific) host defence responses to potential pathogens. From this one can infer that while the microbial components recognised by the LRR domain of most NOD-
LRR proteins are still to be defined, these proteins are also microbial component sensing molecules that play a role in innate immunity. The NOD domain is a central region common to most, if not all, NOD-LRR family members that, on binding of a ligand to the LRR, facilitates a conformational change in the molecule and thus its activation. This conformational change also involves the third region of the molecule, the CARD or PYRIN domains, in that it facilitates the interaction of these effector domains with a "downstream" protein capable of initiating an inflammatory programme. ${ }^{7}$ It should be noted however that the CARD and PYRIN domains interact with different downstream molecules and thus lead to different types of inflammatory responses; thus, while activation of the CARD domain results in activation of nuclear factor kappa B (NFKB), activation of the PYRIN domain leads to activation of procaspase 1 and, ultimately, interleukin (IL)-1 $\beta .^{67}$ Two other points concerning NOD-LRR proteins are firstly that they are intracellular (cytoplasmic) proteins and thus differ from TLRs that are either on the surface of cells or in phagolysomal compartments, and secondly, while the signalling cascades of TLRs and NODs differ very considerably, points of intersection do occur; this introduces the possibility that NOD-LRR family members regulate TLR responses. As we shall see, this is important in the case of NOD2.

A major step forward in the understanding of NOD2 and the structurally similar NOD-LRR family member, NOD1, was the discovery that these molecules bind (via their LRR domains) specific microbial peptides derived from peptidoglycan (PGN), a glycoprotein found in the wall of virtually all bacteria, including those comprising the commensal microbial microflora of the gut. These consist of muramyl dipeptide (MDP) in the case of NOD2 and $\gamma$-D-glutamyl meso diaminopimelic acid in the case of NODl. ${ }^{89}$ As PGN is also a ligand for TLR $2,{ }^{10}$ this finding implies that PGN signals the cell in three ways: at the cell surface as an intact molecule interacting with TLR2 and in the cell cytoplasm as a peptide breakdown product interacting with NOD2 or NOD1. Recently, it has been shown that MDP is also recognised by cryopyrin, ${ }^{11}$ another NOD-LRR family member that is similar to NOD2 and NODl, except that it has a PYRIN region instead of a CARD region; this brings to four the number of ways PGN can signal the cell. Interestingly, as in the case of NOD2, mutations in cryopyrin are also associated with inflammatory diseases. ${ }^{12}$ Finally, studies of the cellular distribution of NOD2 show that it is expressed in antigen presenting cells (APCs) and in a subset of epithelial cells at the base of the intestinal crypts, known as Paneth cells. ${ }^{13}$ Thus it is apparent that NOD2 is well positioned to influence responses to both commensal and pathogenic organisms in the gut. NOD1, on the other hand, is expressed in all columnar epithelial cells and in APCs.

MDP induced NOD2 signalling results in NFKB activation and subsequent NFкB dependent cytokine responses. However, these are much weaker than those elicited by PGN induced TLR2 signalling and may thus be a relatively unimportant aspect of NOD2 function. ${ }^{14} 15$ This is in fact supported by recent studies that show that NOD2 exerts strong regulatory influence on TLR signalling, both positive and negative. An important example of negative regulation that relates to the possible role of NOD2 mutations in Crohn's disease has emerged from studies of NOD2 effects on PGN induced IL-12 and IL-18 production, two cytokines whose synthesis is dependent on activation of NFкB. ${ }^{16}$ These studies have provided evidence that MDP activation of NOD2 induces only low levels of IL-12 (p70 heterodimer) synthesis and, perhaps more importantly, markedly inhibits the capacity of PGN to induce this cytokine. ${ }^{16}$ This negative effect of NOD2 signalling is brought into bold relief by study of cells from NOD2 knockout mice that lack NOD2: such cells produce markedly increased amounts of IL-12. The molecular mechanism of this NOD2 regulatory 
effect appears to involve subtle but important differences in activation of NFKB by PGN in the presence and absence of NOD2 signalling. In the presence of NOD2, PGN signalling results in relatively low amounts of c-Rel translocation to the nucleus, a key event in induction of IL-12 by NFKB. ${ }^{17}$ In contrast, in the absence of NOD2, PGN signalling results in relatively high amount of c-Rel translocation and thus greater amounts of IL-12 synthesis. ${ }^{16}$

As IL-12 is one of the main initiators of the Thl inflammatory response and higher amounts of IL-12 production are reflected in higher interferon $\gamma($ IFN- $\gamma$ ) production, this regulatory effect of NOD2 on PGN responses could be the basis of the fact that NOD2 mutations (and accompanying deficiency in NOD2 function) is a susceptibility factor in Crohn's disease. One could postulate here that the "immunostat" for innate immune responses relating to PGN derived from commensal organisms in the gastrointestinal tract is set to a lower level by the NOD2 mutations so that the mucosal environment in patients with NOD2 mutations produce a higher basal level of IL-12 and thus support Thl responses by any number of antigens derived from ordinarily non-pathogenic organisms in the intestinal microflora. However, while this thesis is compelling in the context of animal models of mucosal inflammation and in mice that are NOD2 deficient, it has yet to be verified in humans.

A second type of regulation of TLR responses exerted by NOD2 signalling is the obverse of that just discussed and involves enhancement of TLR responses. Thus evidence is also at hand showing that NOD2 signalling in human monocytic cell lines has an enhancing effect on IL-8 and tumour necrosis factor (TNF) production induced in these cells by TLR2, TLR4, and TLR9 ligands. ${ }^{18}{ }^{19}$ In addition, as discussed below, NOD2 signalling also has an enhancing effect on TLR9 responses in fresh peripheral blood human cells. These studies indicate that NOD2 modulation of TLR responses can be either positive or negative depending on the types of TLR stimuli.

What molecular mechanisms account for these very different forms of NOD2 regulation? The answer is not yet known but there is some evidence that it involves the way NOD2 and TLRs interact with RICK (RIP2), an adaptor molecule containing a CARD region that links NOD2 and TLR signalling to NFאB activation. As mentioned above, activation of NOD2 by ligand (MDP) binding to its LRR results in a change in conformation of its CARD region. This in turn leads to binding and activation of RICK via a CARD/CARD interaction. Activated RICK then ubiquitinylates the IKK $\gamma$ subunit of the NFKB IKK complex and thus activates IKK $\beta$ and downstream NFKB components. ${ }^{20}$ Interestingly, PGN signalling via TLR2 also leads to activation of RICK by an independent route involving MyD88 (as discussed below) so that the NOD2 and TLR2 signalling pathways intersect at RICK. $^{21}$ This opens the door to the possibility that NOD2 signalling negatively regulates TLR2 signalling with respect to induction of IL-12 by imposing a form of ubiquitinylation on the IKK $\gamma$ subunit of NFKB (different from that induced by TLR2) that leads to decreased c-Rel activation, as discussed above. Within this framework we can also explain enhancement of TLR responses by NOD2 signalling if we assume that some TLR responses, such as the TLR9 response to CpG stimulation, leads to activation of NFкB through activation of a canonical TLR pathway that goes through MyD88, IRAK, and TRAF6 and does not involve RICK, as indicated by the fact that RICK deficient macrophages show normal cytokine responses following $\mathrm{CpG}$ stimulation. ${ }^{1021}$ In addition, even alternative TLR signalling response that moves from MyD88 directly to RICK may not lead to downregulation of cytokine responses except in the case of IL- 12 which is uniquely sensitive to c-Rel activation. On the contrary, here one may see enhancement of TLR responses due to the fact that NOD2 activation upregulates MyD88 expression. ${ }^{22}$

In this issue of the Gut, van Heel and colleagues $^{23}$ report that in conformity with previous studies mentioned above, whereas MDP stimulation of peripheral blood mononuclear cells (PBMCs) from normal individuals results in 2-3-fold enhancement of CpG DNA stimulation of PBMC production of TNF- $\alpha$ and IL-8, such enhancement is not seen in PBMCs from patients with Crohn's disease bearing NOD2 mutations (see page 1553). Concomitant studies of IL- 12 secretion were not reported in this study or in a previous study of normal individuals and Crohn's disease patients with NOD2 mutations, ${ }^{24}$ perhaps because secretion of IL- 12 by PBMCs is low and thus difficult to assess. Thus we do not know if the loss of the enhancing effect of NOD2 is counterbalanced by loss of an inhibitory effect. We also do not know if the same or similar findings would be obtained if the authors had studied intestinal cells that differ considerable from peripheral cells in response to various stimuli. ${ }^{25}$ In any case, based on these findings, van Heel and colleagues ${ }^{23}$ propose that synergistic cytokine response between TLR9 and NOD2 might be beneficial in maintaining intestinal homeostasis and the lack of such synergism is a cause of Crohn's disease.

Intestinal or mucosal homeostasis by any definition is the end result of effector cell responses that protect the individual from infections of the mucosa by pathogens and regulatory responses that protect the individual from excessive responses induced either by pathogens or by commensal organisms in the microflora. ${ }^{26}$ It is doubtful that disruption of mucosal homeostasis by affecting the effector cell part of the equation is the cause of Crohn's disease as the latter is well known to be associated with an excessive Thl immune response, especially one involving TNF- $\alpha$ or IL-12, both cytokines targeted for reduction in the treatment of patients with anti-TNF- $\alpha$ or anti-IL12 antibodies. ${ }^{27}$ Nevertheless, this possibility is worth considering in view of recent information concerning the relation of NOD2 signalling in Paneth cells to the production of $\alpha$-defensins.

Paneth cells are specialised epithelial cells at the base of the intestinal crypts that are characterised by dense granules containing $\alpha$-defensins, peptides with bactericidal properties. ${ }^{29}$ As such, they fulfil an important host defence function in the gut, as shown by the fact that transgenic mice that express human $\alpha$-defensin 5 are resistant to Salmonella typhimurium infection and, conversely, mice lacking the ability to process $\alpha$-defensins into a mature active form are more susceptible to such infection. ${ }^{30}$ Of interest to the present discussion, Paneth cells express TLR9 and, as mentioned earlier, they also express NOD2 $2^{13} 31$ In addition, they can be triggered by $\mathrm{CpGs}$ and by MDP to secrete $\alpha$-defensins. Thus it is reasonable to propose that the presence of NOD2 mutations renders epithelial cells unable to produce maximal amounts of $\alpha$-defensins and, as a result, organisms colonise the intestinal surface that induce the inflammation in Crohn's disease. Consistent with this notion, there is some as yet incomplete evidence that patients with Crohn's disease, particularly those with NOD2 mutations, express decreased amounts of $\alpha$-defensin 5 in the small intestinal mucosa $^{32}$ and one line of mice lacking NOD2 exhibit reduced $\alpha$-defensin mRNA expression in Paneth cells and are more susceptible to oral (but not intravenous) $L$ monocytogenes infection of the liver. ${ }^{33}$ It should be noted however that these data supportive of the concept that NOD2 mutations produce a kind of immunodeficiency state that predisposes to a type of bacterial colonisation 
of the gut are counterbalanced by other data that rule against this concept. Perhaps the most persuasive is that mice that lack MMP-7 (matrilysin) and that thus cannot convert $\alpha$-defensin precursors into mature and active forms of $\alpha$-defensins ${ }^{34}$ or, indeed, mice that lack Paneth cells ${ }^{35}$ altogether, do not spontaneously develop chronic inflammation indicative of a Crohn's diseaselike condition, at least under the pathogen free conditions that are able to support other causes of chronic mucosal inflammation. In addition, convincing data have yet to emerge that the intestinal surface of patients with Crohn's disease or in spontaneous experimental models of Crohn's disease is colonised with organisms that cause Crohn's disease; on the contrary, there is good evidence that commensal organisms have ready access to the internal milieu of the gut, ${ }^{36}$ despite the presence of an intact $\alpha$-defensin system, and thus have the potential to induce Crohn's disease in patients with normal defensin production.

We come then to the second way in which intestinal homeostasis could be disturbed by lack of enhancement of TLR9 responses to CpG by NOD2 responses to $\mathrm{MDP}$ - namely, by the failure of the mucosal immune system in this situation to mount adequate regulatory cell (that is, tolerogenic) responses. The basis of this possibility comes from the recent observation that various forms of experimental colitis in mice are paradoxically prevented by provision of $\mathrm{CpGs}$ either in the form of immunostimulatory oligonucleotides or as components of so-called probiotic organisms. ${ }^{37}{ }^{38}$ Furthermore, this protective effect can be traced to TLR9 stimulation as it is not seen in mice lacking TLR9 by gene targeting or in mice deficient in the signalling of type I IFN, ${ }^{39}$ the cytokine class thought to be produced by plasmacytoid dendritic cells implicated in the induction of regulatory $\mathrm{T}$ cells. ${ }^{40}$ Thus these data suggest that impairment in optimal responses to CpGs via TLR9, such as that caused by lack of enhancement by NOD2 signalling, could lead to deficient regulatory $\mathrm{T}$ cell development and the development of Crohn's disease due to failure to maintain tolerance to commensal organisms.

This is an interesting possibility but one that is far from being proven. Firstly, while there is ample evidence that experimental colitis can be due to deficient regulatory cell responses, there are few data that this is the case in human Crohn's disease. ${ }^{26}$ Secondly, while van Heel and colleagues ${ }^{23}$ have shown that NOD2 signalling enhances TLR9 signalling, ${ }^{23}$ there is no evidence that TLR9 signalling by itself can induce regulatory T cells. Finally, and perhaps most importantly, there is a large body of evidence that under most circumstances TLR9 signalling induces Thl responses (that is, the very type of cytokine response that underlies Crohn's disease). ${ }^{41}$ This may explain the fact that delivery of $\mathrm{CpG}$ to mice with already established inflammation leads to intensified inflammation. ${ }^{42} 43$ The fact is that we still do not know enough about TLR9 signalling and its relation to induction of effector versus regulatory $\mathrm{T}$ cells to predict whether enhancement of TLR9 responses would exacerbate or abate Crohn's disease.

The above discussion shows very clearly that we have gained a great deal of knowledge concerning the role of NOD2 in normal individuals in the past several years. Nevertheless, much remains to be learned concerning its role in disease. We believe that ultimately NOD2 mutations will prove to be the cause of Crohn's disease, primarily because they lead to loss of negative regulatory effects on TLR signalling. However, additional studies in patients with mutations such as the one reported in this issue of Gut will be necessary to elucidate the issue.

Gut 2005;54:1515-1518.

doi: $10.1136 /$ gut.2005.071795

\section{Authors' affiliations}

T Watanabe, A Kitani, W Strober, Mucosal

Immunity Section, Laboratory of Host

Defenses, National Institute of Allergy and

Infectious Diseases, National Institutes of

Health, Bethesda, Maryland, USA

Correspondence to: Dr W Strober, Mucosal Immunity Section, Laboratory of Host Defenses, National Institute of Allergy and Infectious Diseases, National Institutes of Health, Building 10 CRC, Room 5W3940, 10 Center Drive, Bethesda, MD 20892, UŚA

wstrober@niaid.nih.gov

Conflict of interest: None declared.

\section{REFERENCES}

1 Hugot JP, Chamaillard M, Zouali $\mathrm{H}$, et al. Association of NOD2 leucine-rich repeat variants with susceptibility to Crohn's disease. Nature 2001:411:599-603.

2 Ogura $\mathrm{Y}$, Bonen DK, Inohara N, et al. A frameshift mutation in NOD2 associated with susceptibility to Crohn's disease. Nature 2001;411:603-6.

3 Hampe J, Cuthbert A, Croucher PJ, et al. Association between insertion mutation in NOD2 gene and Crohn's disease in German and British populations. Lancet 2001;357:1925-8.

4 Inoue N, Tamura K, Kinouchi Y, et al. Lack of common NOD2 variants in Japanese patients with Crohn's disease. Gastroenterology 2002; 123:86-91.

5 Kanazawa N, Okafuji I, Kambe N, et al. Early onset sarcoidosis and CARD15 mutations with constitutive nuclear factor-kappaB activation: common genetic etiology with Blau syndrome. Blood 2005; 105: 1 195-7.
6 Inohara N, Nunez G. NODs: intracellular proteins involved in inflammation and apoptosis. Nat Rev Immunol 2003;3:371-82.

7 Inohara N, Chamaillard M, McDonald C, et al. NOD-LRR proteins: role in host-microbial interactions and inflammatory disease. Annu Rev Biochem 2005;74:355-83.

8 Inohara N, Ogura Y, Fontalba A, et al. Host recognition of bacterial muramyl dipeptide mediated through NOD2. Implications for Crohn's disease. J Biol Chem 2003;278:5509-12.

9 Chamaillard M, Hashimoto M, Horie $Y$, et al. An essential role for NOD1 in host recognition of bacterial peptidoglycan containing diaminopimelic acid. Nat Immuno 2003:4:702-7

10 Akira S, Takeda K. Toll-like receptor signalling. Nat Rev Immunol 2004;4:499-51 1.

11 Martinon F, Agostini L, Meylan E, et al. Identification of bacterial muramyl dipeptide as activator of the NALP3/cryopyrin inflammasome. Curr Biol 2004; 14:1929-34.

12 Agostini L, Martinon F, Burns K, et al. NALP3 forms an IL-1 beta-processing inflammasome with increased activity in Muckle-Wells autoinflammatory disorder. Immunity 2004;20:319-25.

13 Ogura Y, Lala S, Xin W, et al. Expression of NOD2 in Paneth cells: a possible link to Crohn's ileitis. Gut 2003;52:1591-7.

14 Maeda S, Hsu LC, Liu H, et al. Nod2 mutation in Crohn's disease potentiates NF-kappaB activity and IL-1 beta processing. Science 2005;307:734-8.

15 Pauleau AL, Murray PJ. Role of nod2 in the response of macrophages to toll-like receptor agonists. Mol Cell Biol 2003;23:7531-9.

16 Watanabe T, Kitani A, Murray PJ, et al. NOD2 is a negative regulator of Toll-like receptor 2mediated Thelper type 1 responses. Nat Immunol 2004;5:800-8.

17 Hilliard BA, Mason N, Xu L, et al. Critical roles of c-Rel in autoimmune inflammation and helper $\mathrm{T}$ cell differentiation. J Clin Invest 2002; 1 10:843-50

18 Uehara A, Yang S, Fujimoto Y, et al Muramyldipeptide and diaminopimelic acidcontaining desmuramylpeptides in combination with chemically synthesized Toll-like receptor agonists synergistically induced production of interleukin-8 in a NOD2- and NOD1-dependent manner, respectively, in human monocytic cells in culture. Cell Microbiol 2005;7:53-61.

19 Wolfert MA, Murray TF, Boons GJ, et al. The origin of the synergistic effect of muramyl dipeptide with endotoxin and peptidoglycan. $J$ Biol Chem 2002;277:39179-86.

20 Abbott DW, Wilkins A, Asara JM, et al. The Crohn's disease protein, NOD2, requires RIP2 in order to induce ubiquitinylation of a novel site on NEMO. Curr Biol 2004; 14:2217-27

21 Kobayashi K, Inohara N, Hernandez LD, et al. $\mathrm{RICK} / \mathrm{Rip}$ /CARDIAK mediates signalling for receptors of the innate and adaptive immune systems. Nature 2002;416:194-9.

22 Yang S, Tamai R, Akashi S, et al. Synergistic effect of muramyldipeptide with

lipopolysaccharide or lipoteichoic acid to induce inflammatory cytokines in human monocytic cells in culture. Infect Immun $2001 ; 69: 2045-53$.

23 van Heel DA, Ghosh S, Hunt KA, et al. Synergy between TLR9 and NOD2 innate immune responses is lost in genetic Crohn's disease. Gut 2005;54:1553-7.

24 Netea MG, Ferwerda G, de Jong DJ, et al. Nucleotide-binding oligomerization domain-2 modulates specific TLR pathways for the induction of cytokine release. $J$ Immunol 2005; 174:6518-23.

25 Hirotani T, Lee PY, Kuwata H, et al. The nuclea IkappaB protein IkappaBNS selectively inhibits lipopolysaccharide-induced IL-6 production in macrophages of the colonic lamina propria. $\mathrm{J}$ Immunol 2005; 174:3650-7.

26 Bouma G, Strober W. The immunological and genetic basis of inflammatory bowel disease. Nat Rev Immunol 2003;3:521-33.

27 Targan SR, Hanauer SB, van Deventer SJ, et al. A short-term study of chimeric monoclonal antibody cA2 to tumor necrosis factor alpha for Crohn's 
disease. Crohn's Disease cA2 Study Group. N Engl J Med 1997;337:1029-35.

28 Mannon PJ, Fuss IJ, Mayer L, et al. Antiinterleukin-12 antibody for active Crohn's disease. N Engl J Med 2004;351:2069-79.

29 Ouellette AJ. Defensin-mediated innate immunity in the small intestine. Best Pract Res Clin Gastroenterol 2004;18:405-19.

30 Salzman NH, Ghosh D, Huttner KM, et al. Protection against enteric salmonellosis in transgenic mice expressing a human intestinal defensin. Nature 2003;422:522-6.

31 Rumio $C$, Besusso D, Palazzo $M$, et al. Degranulation of paneth cells via toll-like receptor 9. Am J Pathol 2004; 165:373-81.

32 Wehkamp J, Harder J, Weichenthal $M$ et al. NOD2 (CARD15) mutations in Crohn's disease are associated with diminished mucosal alpha-defensin expression. Gut 2004;53: 1658-64.

33 Kobayashi KS, Chamaillard M, Ogura Y, et al. Nod2-dependent regulation of innate and adaptive immunity in the intestinal tract. Science 2005;307:731-4

34 Wilson CL, Ouellette AJ, Satchell DP, et al. Regulation of intestinal alpha-defensin activation by the metalloproteinase matrilysin in innate host defense. Science 1999;286:113-17

35 Garabedian EM, Roberts $\sqcup$, McNevin MS, et al. Examining the role of Paneth cells in the small intestine by lineage ablation in transgenic mice. J Biol Chem 1997;272:23729-40.

36 Macpherson AJ, Harris NL. Interactions between commensal intestinal bacteria and the immune system. Nat Rev Immunol 2004:4:478-85.

37 Rachmilewitz D, Katakura K, Karmeli F, et al Toll-like receptor 9 signaling mediates the antiinflammatory effects of probiotics in murine experimental colitis. Gastroenterology 2004; 126:520-8.

38 Rachmilewitz D, Karmeli F, Takabayashi K, et al. Immunostimulatory DNA ameliorates experimental and spontaneous murine colitis. Gastroenterology 2002; 122:1428-41.

\section{Following the TRAIL from hepatitis $C$ virus and alcohol to fatty liver}

\section{S C Afford, D H Adams}

\section{Tumour necrosis factor related apoptosis inducing ligand or} TRAIL, is a novel mediator of fatty liver disease which may provide a mechanism to explain the development of steatosis in hepatitis $C$ virus infection and in response to alcohol

$\mathrm{F}$ atty liver or steatosis is a common finding in several liver diseases, most notably non-alcoholic fatty liver disease (NAFLD) and alcoholic liver disease (ALD) but is also seen more frequently in chronic hepatitis $\mathrm{C}$ virus (HCV) related liver disease than would be predicted by simple concurrence of the two diseases. ${ }^{1}$ Several mechanisms have been proposed to explain why steatosis might develop in chronic viral infection, including direct effects of the virus on lipid metabolism, but none of these is entirely convincing. Furthermore, steatosis is not a benign lesion but one that contributes to the progression of fibrosis, not only in NAFLD and ALD but also in HCV, in part by increasing the sensitivity of the liver to oxidative stress and cytokine mediated injury. ${ }^{2}$ The paper by Mundt and colleagues ${ }^{3}$ in this issue of Gut provides novel mechanistic insights into why steatosis develops in HCV and how it might accentuate liver injury (see page 1590). They have concentrated their efforts on a member of the tumour necrosis factor (TNF) superfamily called TRAIL or TNF related apoptosis inducing ligand. TRAIL is known to induce apoptosis in transformed cells and this group have previously shown TRAIL, acting through one of its receptors called TRAIL-DR5 or TRAIL-2, mediates hepatocyte apoptosis in viral hepatitis. What they now show is that this receptorligand pair can also mediate hepatic steatosis in both viral hepatitis and in response to alcohol.

The authors start with the observation that expression of TRAIL is increased in the livers of patients with HCV associated steatosis and they then proceed to investigate the functional relevance of these observations in animal models. They used adenoviral gene transfer to express TRAIL in mouse liver and found that overexpression of TRAIL itself had if gene transfer of TRAIL was preceded by high dose adenoviral infection, this sensitised the liver to respond to TRAIL expression with steatosis and hepatocyte apoptosis. Furthermore, by looking at expression of TRAIL receptors in the infected livers, the authors were able to show that viral infection downregulates a TRAIL decoy receptor while increasing expression of the death domain associated TRAIL receptor TRAIL-R2, thereby providing a mechanism to explain how viral infection can amplify no effect in the healthy liver. However,
39 Katakura K, Lee J, Rachmilewitz D, et al. Toll-like receptor 9-induced type I IFN protects mice from experimental colitis. J Clin Invest 2005:115:695-702.

40 Bilsborough J, George TC, Norment A, et al. Mucosal CD8alpha+ DC, with a plasmacytoid phenotype, induce differentiation and support function of $\mathrm{T}$ cells with regulatory properties. Immunology 2003;108:481-92.

41 Vollmer J. Progress in drug development of immunostimulatory CpG oligodeoxynucleotide ligands for TLR9. Expert Opin Biol The 2005;5:673-82.

42 Obermeier F, Dunger N, Deml L, et al. CpG motifs of bacterial DNA exacerbate colitis of dextran sulfate sodium-treated mice. Eur J Immunol 2002;32:2084-92

43 Obermeier F, Dunger N, Strauch UG, et al. Contrasting activity of cytosin-guanosin dinucleotide oligonucleotides in mice with experimental colitis. Clin Exp Immunol 2003;134:217-24. the effects of TRAIL. Furthermore, induction of steatosis was specific for TRAIL because overexpression of another TNFSF member Fas-L was associated with apoptosis but not steatosis.

Because nuclear factor $\kappa \mathrm{B}(\mathrm{NF} \kappa \mathrm{B})$ activity is critical in determining the outcome of activation of many TNF receptors, the authors then investigated the effects of inhibiting NFKB and found that the loss of NFKB activation markedly sensitised hepatocytes to TRAIL mediated apoptosis and also resulted in the accumulation of larger amounts of fat in hepatocytes. Finally, because TNF- $\alpha$ plays an important role in alcoholic fatty liver disease, they investigated whether alcohol could sensitise mice to the effects of TRAIL. Intriguingly, feeding mice with $20 \%$ ethanol for four days did not lead to changes in TRAIL receptors but did sensitise animals to subsequent exposure to TRAIL but in contrast with virus infection ethanol led only to steatosis in response to TRAIL and not to apoptosis. TNF- $\alpha$ has been shown to mediate steatosis via effects on insulin resistance which can be inhibited by treatment with metformin leading the authors to investigate metformin treatment in their model. However, metformin had no protective effect on TRAIL mediated steatosis, suggesting that TRAIL induced steatosis is a direct consequence of TRAIL-R2 activation.

These observations are of major significance because they show that TRAIL is a novel mediator of fatty liver disease which may provide a mechanism to explain the development of steatosis in HCV infection. Furthermore, the fact that TRAIL expression is harmless in healthy livers whereas in the presence of viral infection it mediates hepatocyte apoptosis and steatosis and after alcohol mediates steatosis without apoptosis suggests that the outcome of TRAIL-2 


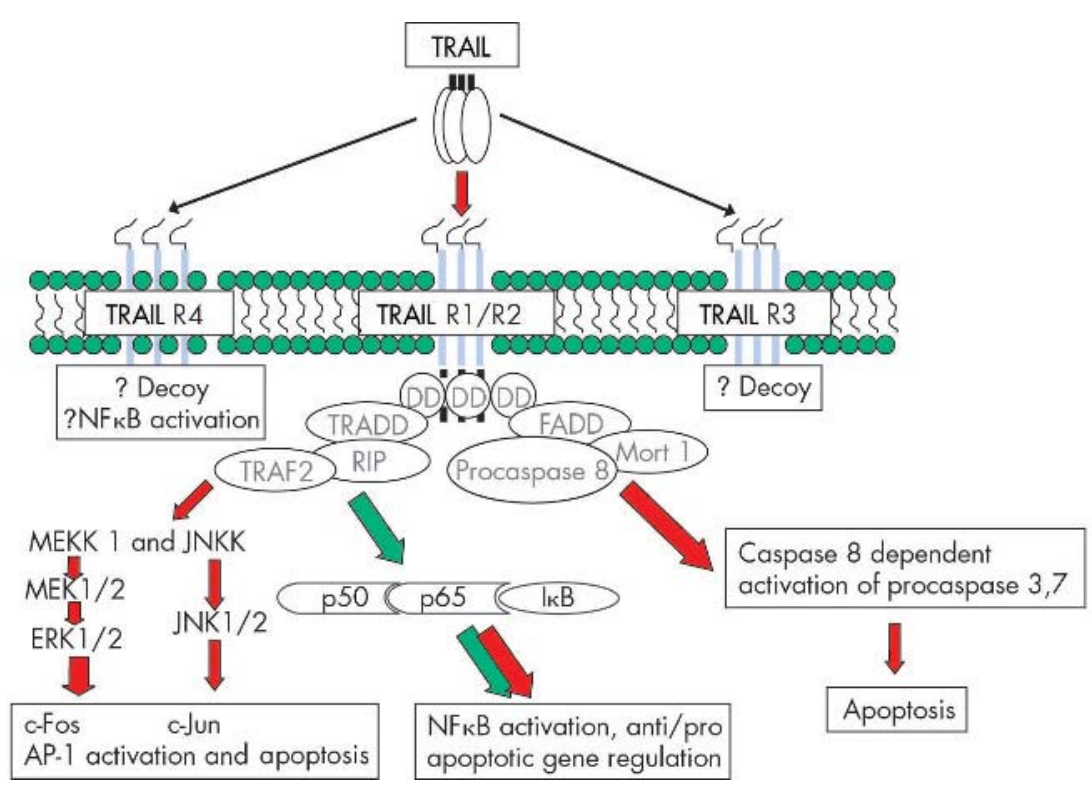

Figure 1 Tumour necrosis factor related apoptosis inducing ligand (TRAIL) receptor signalling. Schematic diagram showing the major intracellular signalling pathways activated following TRAIL ligation of its membrane bound receptors. For TRAIL receptors 1 and 2 (TRAIL-R1 and TRAIL-R2) the dominant pathway is initiation of apoptosis. However, the ability to activate nuclear factor $\kappa B$ (NFKB) and c-Jun may modulate the outcome by inducing expression of both antiapoptotic and proapoptotic signals. Current evidence suggests that TRAlL-R4 may be able to activate NFKB, providing a mechanism by which it could antagonise the proapoptotic effects of TRAIL-R2 activation (adapted from Kimberley and Screaton ${ }^{16}$ and MacFarlane ${ }^{19}$ ).

activation will depend on the presence of local signals, including those mediated by other TNF family members. These data provide an exciting new insight into the pathogenesis of steatosis but also raise a note of caution for the clinical trials of TRAIL which, at present, show considerable promise for the treatment of malignant disease, including hepatocellular carcinoma..$^{4-6}$ Thus the authors suggest that all trials involving TRAIL should consider the potential hepatotoxic side effects, particularly in patients with inflammatory, viral, and/or alcohol related liver disease.

There are at least 19 identified TNF superfamily ligands capable of binding to one or more of the 27 identified members of the TNF receptor (TNFR) superfamily. ${ }^{7}$ Several of these receptor ligand pairs are expressed in the liver, some constitutively and some at sites of active inflammation, ${ }^{8}$ making interpretation of the pathophysiological significance of interactions between any of these receptors and their ligands difficult. However, the study of Mundt and colleagues $^{3}$ reinforces the potential benefits from studying the biological functions of this family of molecules in physiologically relevant model systems. TNFRs are seldom expressed in isolation on any particular cell type, and are usually found in combinations that regulate a wide range of functions, sometimes in an apparently cell specific of biological functions in many cell types. In the liver, they are involved in modulating cell survival and apoptosis, in epithelial, endothelial, and stromal cells. They are crucial for the control of liver growth and regeneration as well as mediating the consequences of both acute and chronic inflammation. ${ }^{13}$ TRAIL, which was originally identified by virtue of its sequence homology to Fas ligand, is a type II transmembrane protein with 281-291 amino acids and an extracellular region which is cleaved as a soluble molecule. ${ }^{14}$ TRAIL is upregulated on the membrane of activated lymphocytes, including hepatic NK and NK T cells, and secreted by neutrophils and monocytes on exposure to type 1 interferons. ${ }^{16}$ A major difference between TRAIL and CD95L or TNF$\alpha$ is its ability to induce apoptosis of cell lines and tumour cells while displaying minimal toxicity on normal cells. ${ }^{17}$ This led to interest in TRAIL as a therapy for cancer and subsequent clinical trials with soluble TRAIL. ${ }^{18}$ There are currently four known membrane receptors for TRAIL and one dimeric soluble secreted receptor, osteoprotegerin. ${ }^{16}$ TRAIL-R1 and TRAIL-R2 are classical TNF receptors and contain a cytoplasmic death domain (which is also present in other family members, including TNFRl and $\mathrm{Fas}^{19}$ ) and can activate both caspases and NFKB (fig 1). The other two membrane receptors, TRAIL-R3 (DcRl) and TRAIL-R4 (DcR2), have truncated death domains and are not capable of activating the caspase cascade. This led to the assumption that they act as decoy receptors but they may activate NFKB and block apoptosis ${ }^{16}$ and it is possible, given the precedent with other TNFRs including TNFR2, CD40, and CD30, that they might promote apoptosis via autocrine or paracrine activation of other TNFRl and Fas. ${ }^{11}$

The true biological function of TRAIL has been difficult to define but current evidence suggests that its main function is as a regulator of the innate immune response during immune surveillance against tumours and virus infected cells. ${ }^{15} 18$ The study by Mundt and colleagues $^{3}$ provides further evidence that TRAIL is a critical determinant of outcome and tissue damage in inflammatory liver disease. Given the prominent role of TNF- $\alpha$ in the pathogenesis of steatohepatitis, ${ }^{2021}$ it was logical to investigate other members of the TNF superfamily. TRAIL was particularly interesting because tumour cells were thought to be sensitive to TRAIL induced apoptosis whereas normal hepatocytes were not ${ }^{22}$ although such assumptions were probably too simplistic. ${ }^{23}$ TRAIL-R2 appears to be similar to other members of the TNFR family in having a potential role in the clearance of virally infected cells, including hepatitis $\mathrm{B}_{1}^{2425}$ but what is novel about the 
current study is the ability of TRAIL acting through TRAIL-R2 to induce steatosis as well as apoptosis. The authors show that the outcome of TRAIL-R2 activation is determined by the presence or absence of viral infection or toxic agents such as alcohol. Elucidating the mechanisms behind these effects will be important for understanding why particular disease triggers are associated with specific patterns of liver injury. The viral effect may be a consequence of the release of type 1 and type 2 interferons which can induce TRAIL expression on immune effector cells and prime cells for TNF mediated steatosis. ${ }^{24}$ Furthermore, transfection of Hep G2 cells with the HBV encoded $X$ antigen increases their sensitivity to TRAIL mediated apoptosis, suggesting that some viral protein may have direct effects on this pathway. ${ }^{25}$ The mechanisms by which ethanol promotes TRAIL mediated steatosis is even less clear. Both apoptosis and steatosis mediated by TRAIL are accentuated if $\mathrm{NF \kappa B}$ is inactivated, suggesting that $\mathrm{NF \kappa B}$ plays a protective role. ${ }^{1826}$ Thus some of increased sensitivity to the effects of TRAIL in inflammatory liver disease may be a consequence of alterations in NFKB activation, possibly as a result of signals provided by other TNF family members. ${ }^{24}$

It is not clear whether TRAIL in these models is presented as a membranous ligand by haematopoietic cells, as an autocrine/paracrine signal on hepatocytes, or as a soluble cytokine. Previous work in murine models of liver inflammation suggests that TRAIL expression on mononuclear cells is sufficient to drive liver damage ${ }^{27}$ but in models of adenoviral infection lymphocyte TRAIL is not necessary, suggesting a paracrine/ autocrine mechanism involving hepatocyte TRAIL. ${ }^{24}$ In addition, TRAIL may be operating through other liver cell types. Apoptosis of stellate cells is an important component of the resolution phase of hepatic fibrosis ${ }^{28}$ and activated stellate cells show increased expression of TRAIL-R2 and increased sensitivity to apoptosis by TRAIL. ${ }^{29}$ The function of soluble TRAIL may prove to be important for the future of clinical trials with TRAIL. So far hepatotoxicity does not appear to have been a major side effect of TRAIL therapy but clearly from the study of Mundt and colleagues ${ }^{3}$ the chances of toxicity will be greater in patients with concomitant liver disease, many of whom will be screened out of phase $1 / 11$ clinical trials and treated. Animal studies suggest that soluble TRAIL administered in vivo is much less likely to induce liver injury compared with membrane bound TRAIL. This may be because soluble TRAIL cannot engage death receptors as efficiently as membrane TRAIL or even because the soluble form inhibits activity of membrane TRAIL, as has been shown for soluble and membrane bound Fas-L.

Mundt and colleagues ${ }^{3}$ conclude that TRAIL may be a new therapeutic target for inhibition of hepatic steatosis. However, before this can become a reality, more needs to be known about the complex regulation and interplay of the different TNF family members in the context of liver inflammation. A further caveat also arises from the important differences between the murine and human TRAIL systems. Mice only express one death receptor, which is structurally related to human TRAIL-R2, and the mouse homologues of human TRAIL-R3 and TRAIL-R4 show distinct differences in structure with their human counterparts, suggesting independent evolutionary origins from the human receptors. Thus it is important to interpret results obtained with mouse models with caution before extrapolating them to humans. ${ }^{1618}$

Gut 2005;54:1518-1520.

doi: $10.1136 /$ gut.2005.067801

\section{Authors' affiliations}

S C Afford, D H Adams, Liver Research Laboratories and MRC Centre for Immune Regulation, Institute for Biomedical Research, Queen Elizabeth Hospital, University of Birmingham, Birmingham, UK

Correspondence to: Professor D Adams, Liver Research Laboratories, Institute for Biomedical Research, University of Birmingham Medical School, Wolfson Drive, Birmingham B15 2T, UK; d.h.adams@bham.ac.uk

Conflict of interest: None declared.

\section{REFERENCES}

1 Lonardo A, Adinolfi LE, Loria $\mathrm{P}$, et al. Steatosis and hepatitis $C$ virus: mechanisms and significance for hepatic and extrahepatic disease. Gastroenterology 2004;126:586-97.

2 Tilg H, Diehl AM. Cytokines in alcoholic and nonalcoholic steatohepatitis. N Engl J Med 2000;343: 1467-76.

3 Mundt B, Wirth T, Zender L, et al. Tumour necrosis factor related apoptosis inducing ligand (TRAIL) induces hepatic steatosis in viral hepatitis and after alcohol intake. Gut 2005;54:1590-6.

4 Yagita H, Takeda K, Hayakawa Y, et al. TRAIL and its receptors as targets for cancer therapy. Cancer Sci 2004:95:777-83.

5 Fiorucci G, Vannucchi S, Chiantore MV, et al. TNF-related apoptosis-inducing ligand (TRAIL) as a pro-apoptotic signal transducer with cancer therapeutic potential. Curr Pharm Des 2005; 11:933-44.

6 Ganten TM, Haas TL, Sykora J, et al. Enhanced caspase-8 recruitment to and activation at the DISC is critical for sensitisation of human hepatocellular carcinoma cells to TRAlL-induced apoptosis by chemotherapeutic drugs. Cell Death Differ 2004;11(suppl 1):S86-96.

7 Aggarwal BB. Signalling pathways of the TNF superfamily: a double-edged sword. Nat Rev Immunol 2003;3:745-56.

8 Streetz K, Leifeld L, Grundmann D, et al. Tumor necrosis factor alpha in the pathogenesis of human and murine fulminant hepatic failure. Gastroenterology 2000; 119:446-60.

9 Muppidi JR, Tschopp J, Siegel RM. Life and death decisions: secondary complexes and lipid rafts in TNF receptor family signal transduction. Immunity 2004;21:461-5.

10 Smith CA, Farrah T, Goodwin RG. The TNF receptor superfamily of cellular and viral proteins: activation, costimulation, and death. Cell 1994:76:959-62.

11 Afford SC, Randhawa S, Eliopoulos AG, et al. CD40 activation induces apoptosis in cultured human hepatocytes via induction of cell surface fas ligand expression and amplifies fas-mediated hepatocyte death during allograft rejection. J Exp Med 1999;189:441-6.

12 Grell M, Zimmermann G, Gottfried E, et al. Induction of cell death by tumour necrosis factor (TNF) receptor 2, CD40 and CD30: a role for TNF-R1 activation by endogenous membraneanchored TNF. EMBO J 1999;18:3034-43.

13 Yamada Y, Fausto N. Deficient liver regeneration after carbon tetrachloride injury in mice lacking type 1 but not type 2 tumor necrosis factor receptor. Am J Pathol 1998;152:1577-89.

14 Krammer PH, Dhein J, Walczak H, et al. The role of APO-1-mediated apoptosis in the immune system. Immunol Rev 1994;142:175-91.

15 Baker SJ, Reddy EP. Modulation of life and death by the TNF receptor superfamily. Oncogene 1998;17:3261-70

16 Kimberley FC, Screaton GR. Following a TRAIL: update on a ligand and its five receptors. Cell Res 2004; 14:359-72.

17 Ashkenazi A, Dixit VM. Apoptosis control by death and decoy receptors. Curr Opin Cell Biol 1999; 1 1:255-60.

18 Fulda S, Debatin KM. Modulation of TRAIL signaling for cancer therapy. Vitam Horm 2004;67:275-90.

19 MacFarlane M. TRAIL-induced signalling and apoptosis. Toxicol Lett 2003;139:89-97.

20 Diehl AM. Tumor necrosis factor and its potential role in insulin resistance and nonalcoholic fatty liver disease. Clin Liver Dis 2004;8:619-38.

21 Tilg H, Diehl AM. Cytokines in alcoholic and nonalcoholic steatohepatitis. N Engl J Med 2000;343:1467-76

22 Hao C, Song JH, Hsi B, et al. TRAlL inhibits tumor growth but is nontoxic to human hepatocytes in chimeric mice. Cancer Res 2004;64:8502-6.

23 Mori E, Thomas M, Motoki K, et al. Human normal hepatocytes are susceptible to apoptosis signal mediated by both TRAIL-R1 and TRAIL-R2. Cell Death Differ 2004; 11:203-7.

24 Mundt B, Kuhnel F, Zender L, et al. Involvement of TRAIL and its receptors in viral hepatitis. FASEB $J$ 2003;17:94-6.

25 Janssen $\mathrm{HL}$, Higuchi $\mathrm{H}$, Abdulkarim A, et al. Hepatitis B virus enhances tumor necrosis factorrelated apoptosis-inducing ligand (TRAIL) cytotoxicity by increasing TRAIL-R1/death receptor 4 expression. $J$ Hepatol 2003;39:414-20.

26 Zender L, Hutker S, Mundt B, et al. NFkappaBmediated upregulation of bcl-xl restrains TRAILmediated apoptosis in murine viral hepatitis. Hepatology 2005;41:280-8.

27 Zheng SJ, Wang P, Tsabary G, et al. Critical roles of TRAIL in hepatic cell death and hepatic inflammation. J Clin Invest 2004;1 13:58-64.

28 Duffield JS, Forbes SJ, Constandinou CM, et al. Selective depletion of macrophages reveals distinct, opposing roles during liver injury and repair. J Clin Invest 2005; 1 15:56-65.

29 Taimr P, Higuchi H, Kocova E, et al. Activated stellate cells express the TRAIL receptor-2/death receptor- 5 and undergo TRAIL-mediated apoptosis. Hepatology 2003;37:87-95. 
Hepatitis B

\section{Predicting survival in hepatitis B}

\section{Sherman}

\section{Alanine aminotransferase (ALT) level alone is not an appropriate indication for therapy in chronic hepatitis B infection, and other criteria in addition to ALT must be used to determine eligibility for therapy}

$\mathrm{P}$ redictors of survival in chronic hepatitis B infection are surprisingly not well described. Various studies have identified different factors that were associated with adverse outcomes. For example, Niederau and colleagues, ${ }^{1}$ in a cohort of European patients, identified lack of clearance of hepatitis $\mathrm{B}$ e antigen (HBeAg) as a predictor of decreased survival. Others have identified older age, presence of cirrhosis, and the persistence of alanine aminotransferase (ALT) elevations as adverse prognostic signs in an antibody to hepatitis B e antigen (anti-HBe) positive cohort. ${ }^{2}$ In patients undergoing a flare of hepatitis B activity, whether spontaneous or chemotherapy induced, the presence of jaundice is an ominous sign. ${ }^{3}$ None of these adverse predictive factors are unexpected. Clearly, jaundice, cirrhosis, older age, and elevated ALT are obvious adverse predictive factors but until recently we have not had the tools to predict, years in advance, the outcome of chronic hepatitis B infection. This is important because we would prefer to offer treatment only to those who are likely to develop complications of the disease, and not to those whose disease will become inactive without long term sequelae. Recently, new predictors of outcome have been identified. At last year's American Association for Study of Liver Disease (AASLD) meeting and the recent European Association for Study of the Liver (EASL) meeting, new data were presented that contribute to this debate. In addition, the article by Yuen and colleagues ${ }^{4}$ in this issue of Gut also forces us to re-examine some of our assumptions about hepatitis B prognosis and therefore treatment (see page 1610).

To some extent our current management algorithms have been directed by the pharmaceutical industry because management algorithms tended to follow the design of clinical trials used to license products. For example, the initial registration trials with lamivudine lasted one year. ${ }^{56}$ However, it has since become clear that for most patients one year of therapy with lamivudine (or any nucleoside analogue) provides inadequate seroconversion rates in $\mathrm{HBeAg}$ positive patients. It is also clear that most anti-HBe positive patients require extended, perhaps lifelong, therapy. Trials in HBeAg positive subjects chose HBeAg seroconversion as an end point because historically, seroconversion to anti-HBe positive was considered to be associated with inactivation of disease, with lower levels of viral replication and less inflammation. ${ }^{6}$ It now seems that e antigen seroconversion may be an inappropriate end point for many patients. At best interferon treatment only induces $\mathrm{e}$ antigen seroconversion in $30-35 \%$ of patients. ${ }^{7}$ The durability of this seroconversion is poor. ${ }^{8}$ The proportion of "sero-reverters" is even higher after seroconversion induced by one year of lamivudine therapy.8 ${ }^{8}$ Thus although randomised controlled studies have shown an increased seroconversion rate compared with controls in the short term, it is not clear that treatment induces more patients to undergo HBeAg seroconversion over the long term than would be expected without treatment.

Is it possible that treatment merely advances seroconversion by some uncertain period of time in those who are destined to seroconvert spontaneously at some future point? Perhaps therapy induced seroconversion merely advances spontaneous seroconversion by some years. An argument in favour of this hypothesis is that whether patients are treated with interferon or nucleoside analogues, those who have the highest likelihood of HBeAg seroconversion, namely those who have high ALT and low hepatitis B virus (HBV) DNA concentrations, are also those who have the highest likelihood of spontaneous seroconversion. Furthermore, Yuen and colleagues ${ }^{10}$ have observed matched cohorts of patients treated or not treated with interferon over an extended follow up period and have shown that beyond five years of follow up the proportion of treated patients who underwent seroconversion was the same as in the untreated group (that is, interferon therapy did not increase the overall number of patients undergoing seroconversion). It did however advance seroconversion by about five years. Nor did interferon therapy affect outcome. A study in children reached the same conclusion. ${ }^{11}$ Thus although in some populations treatment induced seroconversion appears to improve prognosis in the short term, it is not certain that treatment increases the overall number of patients undergoing e antigen seroconversions over the long term or improves the prognosis over the longer term.

Given the uncertainty about appropriate treatment end points, it is perhaps not surprising that the indications chosen for starting therapy have also been unsatisfactory. As the overall objective of treatment is to decrease inflammation, and hopefully thereby prevent all of the other complications of chronic hepatitis B, it seems logical to use an elevated ALT, a marker of hepatic inflammation, as an indication to start treatment. All of the registration trials have used this indication. All of the guidelines issued by various continental hepatology societies (AASLD, EASL, Asian Pacific Association for Study of the Liver $)^{12-14}$ supported the use of this indication. However, using elevated ALT as an indication for therapy means that only a small minority of all hepatitis B carriers will ever be treated, far fewer than the $20-25 \%$ of hepatitis B carriers who will die of complications of their liver disease. Using ALT as an indication for therapy will leave many patients who are destined to develop cirrhosis or hepatocellular carcinoma (HCC) untreated. The study by Yuen and colleagues ${ }^{4}$ in this issue of Gut, together with conclusions from a large scale prospective study in Taiwan, ${ }^{15}$ supports the conclusion that ALT alone is not an appropriate indication for therapy. In the Yuen study, patients who had an ALT concentration in the upper range of normal had an increased mortality from HCC compared with those in whom ALT levels were less than $<0.5 \times$ ULN. Paradoxically, the risk of HCC in patients with ALT levels that were higher than $2 \times$ ULN was lower than in patients with lower ALT levels. Yuen et al explain this anomaly by assuming that higher levels of ALT represent flares similar to acute hepatitis, which resolve without leaving significant permanent injury. However, there may also be some selection bias influencing these results, in that patients with ALT $>2 \times$ ULN that persisted over time might have undergone therapy and been excluded from 
this study. Others might have been in the process of seroconverting and going into remission. Yuen and colleagues ${ }^{4}$ also showed that the HBeAg status and ALT on follow up did not correlate with the incidence of complications. When they analysed HBV DNA they found, as did Chu and colleagues, ${ }^{16}$ that HBV DNA below $10^{5}$ copies $/ \mathrm{ml}$ did not protect against the development of complications.

The REVEAL study is one of three similar large scale, long term, prospective, cohort studies of hepatitis B carriers, all of which provide new evidence about identifying patients at risk of a poor outcome. The studies were performed in a cohort in Philadelphia, ${ }^{17}$ a cohort in Haimen City China, ${ }^{18}{ }^{19}$ and in a cohort from several townships in Taiwan. ${ }^{15}$ 20-22 Each cohort included more than 3000-4000 subjects who were recruited and followed for more than 10 years. The end points in all three were similar: incidence of HCC, cirrhosis, and death from liver disease. All three studies came to similar conclusions. The best predictor of an adverse outcome in a hepatitis B carrier was the HBV DNA concentration. The higher the HBV DNA the higher the incidence of an adverse outcome. Neither ALT $^{15} 22$ nor e antigen status ${ }^{20}$ at recruitment was correlated with outcome. These results, together with the data of Yuen and colleagues, ${ }^{4}$ support the concept that patients with normal ALT levels can no longer be excluded from therapy, and that criteria other than the ALT must be used to determine eligibility for therapy.

How then can we distinguish between those hepatitis B carriers who need therapy and those who do not? Are there other markers of a poor prognosis that might be more useful? Liver biopsy showing fibrosis or cirrhosis may be one such marker but we cannot biopsy every hepatitis B carrier. Perhaps non-invasive measurements of fibrosis will help answer this question. However, if treatment is restricted to patients with advanced fibrosis the incidence of cancer might not fall a great deal. The only other logical marker is HBV DNA concentration. The three large cohort studies strongly suggest (but do not prove) that suppression of viral replication will decrease the incidence of adverse outcomes. There is other evidence to support this notion. Long term suppression of woodchuck hepatitis virus replication by entecavir leads to a reduction in the incidence of HCC. ${ }^{23}$ Suppression of viral replication in cirrhotic patients decreases the incidence of liver related adverse events (HCC and cirrhosis). ${ }^{24}$ (Whether suppression of HBV DNA before the onset of cirrhosis would have a similar effect is not known, and is unlikely to be studied, given the difficulty of maintaining a patient with active disease off therapy for an extended period of follow up.) Patients in whom viral replication is spontaneously suppressed early in the course of their disease are at a much lower risk of cirrhosis and HCC compared with those in whom viral replication persists. $^{25} 26$ Finally, in the Taiwan cohort, patients in whom HBV DNA spontaneously improved had a lower incidence of adverse outcomes than those in whom HBV DNA levels remained high. ${ }^{27}$

This all suggests that a high HBV DNA concentration should be the prime indication for therapy. Several immediate questions arise. Firstly, at what point in the natural history is it appropriate to start treatment? This question cannot be answered at present and will have to await full publication of the cohort studies so that the relationship between HBV DNA, age at recruitment, and outcome can be evaluated. The next question is how low should the HBV DNA level be to have the highest likelihood of preventing complications of chronic HBV infection. In the three cohort studies, even HBV DNA concentrations $<100000$ copies/ml were associated with a significant incidence of HCC, cirrhosis, and death from liver disease. Others have shown, in a small cohort, that all those with HCC had an HBV DNA concentration above $2 \times 10^{4} .{ }^{28}$ Until this level can be confirmed as "safe", it is probably wise to aim to suppress HBV DNA maximally, to undetectable levels, or if that is not possible, to below $10^{4}$ copies $/ \mathrm{ml}$.

Until recently we have not had adequate tools to achieve optimal suppression of viral replication indefinitely. Interferon based therapy only induces permanent suppression in a small proportion of patients. ${ }^{59} 30$ There are as yet no long term studies on the durability of pegylated interferon response, but at best, only $30-35 \%$ of HBeAg positive patients respond, leaving $65-70 \%$ requiring additional treatment. ${ }^{31}$ Lamivudine cannot be used long term because of the development of resistance. ${ }^{32}$ The prospect of using adefovir long term is also fading, as up to $18 \%$ resistance rates at four years have been reported..$^{33}$ Entecavir is the most potent nucleoside analogue to complete phase III testing and, so far, no resistance has been reported in the treatment of naïve subjects. ${ }^{34}$ Tenofovir is more potent than adefovir ${ }^{35}$ but its HBV resistance profile and frequency of emergence of resistance remains unknown. However, it is inevitable that resistance will develop over time for both of these agents. There are as yet no data on the combined use of more than one nucleoside analogue, although this would seem to be a logical approach and perhaps the only approach that might provide long term viral suppression.

Given the above considerations, the time has come to abandon some of our old concepts about the management of hepatitis B. We should no longer rely on an elevated ALT to select patients for treatment. Patients with high viral loads and normal ALT levels are not good candidates for interferon and should probably only be treated with nucleos(t)ide analogues. Treatment should aim to suppress viral replication as much as possible. The target should be undetectable HBV DNA and if that is not possible, HBV DNA should not exceed $10^{4}$ copies/ $\mathrm{ml}$. The availability of more potent drugs such as entecavir, telbivudine, and clevudine will make these targets feasible. To ensure long term suppression we have to prevent the emergence of resistance. It may be that if viral replication is suppressed deeply enough, even with monotherapy, resistance will be rare, but addition of a second agent that does not have cross reactive resistance might be necessary. Cost will be a huge issue once we contemplate long term therapy, which will have to be confronted head-on. I believe that we will have to bite the bullet and immediately undertake studies of combination therapy, or risk creating strains of virus that are resistant to everything.

\section{SUMMARY}

- ALT is a poor predictor of outcome and therefore cannot be used as the sole indication for therapy.

- HBeAg positivity is associated with a higher risk of adverse outcomes than anti-HBe positivity.

- HBV DNA concentration at recruitment and during follow up is the best predictor of an adverse outcome.

- The higher the HBV DNA concentration (above $10^{4}$ copies $/ \mathrm{ml}$ ), the greater the mortality.

- Treatment should be aimed at suppressing HBV DNA maximally, to below $10^{4}$, and preferably to below $10^{3}$.

Gut 2005;54:1521-1523.

doi: $10.1136 /$ gut.2005.071332

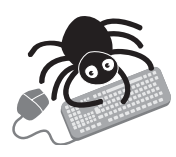

Conflict of interest: declared (the declaration can be viewed on the Gut website at http://www.gutjnl.com/ supplemental).

Correspondence to: $\operatorname{Dr} M$ Sherman, University of Toronto and University Health Network, Toronto General Hospital, 200 Elizabeth St, Toronto, Ontario M5G 2C4, Canada; morris.sherman@uhn.on.ca 


\section{REFERENCES}

1 Niederau C, Heintges T, Lange S, et al. Long-term follow-up of $\mathrm{HBeAg}$-positive patients treated with interferon alfa for chronic hepatitis B. NEng/ J Med 1996;334:1422-7.

2 Papatheodoridis GV, Manesis E, Hadziyannis SJ. The long-term outcome of interferon-alpha treated and untreated patients with $\mathrm{HBeAg}$-negative chronic hepatitis B. J Hepatol 2001;34:306-13.

3 Chan HL, Tsang SW, Hui Y, et al. The role of lamivudine and predictors of mortality in severe flare-up of chronic hepatitis B with jaundice. $J$ Viral Hepat 2002;9:424-8.

4 Yuen M-F, Yuan H-J, Wong DK-H, et al. Prognostic determinants for chronic hepatitis B in Asians: therapeutic implications. Gut 2005; 54:1610-4

5 Schalm SW, Heathcote J, Cianciara J, et al. Lamivudine and alpha interferon combination treatment of patients with chronic hepatitis B infection: a randomized trial. Gut 2000;46:562-8

6 Tassopoulos NC, Volpes R, Pastore G, et al. Efficacy of lamivudine in patients with hepatitis $B$ antigen-negative/hepatitis $B$ virus DNA-positive (precore mutant) chronic hepatitis B. Lamivudine Precore Mutant Study Group. Hepatology 1999:29:889-96.

7 Wong DK, Cheung AM, O'Rourke K, et al. Effect of alpha-interferon treatment in patients with hepatitis $B$ e antigen-positive chronic hepatitis B. A meta-analysis. Ann Intern Med 1993; 119:312-23.

8 van Nunen $A B$, Hansen BE, Suh DJ, et al. Durability of $\mathrm{HBeAg}$ seroconversion following antiviral therapy for chronic hepatitis B: relation to type of therapy and pretreatment serum hepatitis $B$ virus DNA and alanine aminotransferase. Gut 2003;52:420-4

9 Song BC, Suh DJ, Lee HC, et al. Hepatitis B e antigen seroconversion after lamivudine therapy is not durable in patients with chronic hepatitis $B$ in Korea. Hepatology 2000;32:803-6.

10 Yuen MF, Hui CK, Cheng CC, et al. Long-term follow-up of interferon alfa treatment in Chinese patients with chronic hepatitis $B$ infection: The effect on hepatitis $B$ e antigen seroconversion and the development of cirrhosis-related complications. Hepatology $2001 ; 34: 139-45$.

11 Marx G, Martin SR, Chicoine JF, et al. Long-term follow-up of chronic hepatitis $B$ virus infection in children of different ethnic origins. J Infect Dis 2002; 186:295-301.
12 Lok AS, McMahon BJ. Practice Guidelines Committee, American Association for the Study of Liver Diseases (AASLD). Chronic hepatitis B: update of recommendations, Hepatology 2004;39:857-61

13 de Franchis R, Hadengue A, Lau G, et al. EASL International Consensus Conference on Hepatitis B. 13-14 September, 2002 Geneva, Switzerland. Consensus statement. J Hepatol 2003;39/suppl 1):P3-25.

14 Liaw YF, Leung N, Guan R, et al. Asian-Pacific Consensus Working Parties on Hepatitis B. AsianPacific consensus statement on the management of chronic hepatitis B: an update, J Gastroenterol Hepato 2003; 18:239-45.

15 lloeje UH, Yang HI, Su J, et al. Viral load is a strong predictor of hepatocellular carcinoma risk in people chronically infected with hepatitis B virus and with normal serum alanine aminotransferases. J Hepatol 2005;42(suppl 2): 179

16 Chu CJ, Hussain M, Lok AS. Quantitative serum HBV DNA levels during different stages of chronic hepatitis B infection. Hepatology 2002:36: 1408-15.

17 Evans AA, Fabre RE, Chen G, et al. Hepatitis B viral load is associated with the development of hepatocellular carcinoma. Hepatology 2004:40(suppl 1):602A

18 Chen G, Lin WY, Shen FM, et al. Viral load as a predictor of mortality from hepatocellular carcinoma and chronic liver disease in chronic hepatitis B infection. J Hepatol 2005;42(suppl 2): 172

19 Chen G, Lin W, Shen FM, et al. Viral load as a predictor of liver disease in chronic hepatitis $B$ infection. Hepatology 2005;40(suppl 1):594A.

20 Chen CJ, Yang HI, Su J, et al. Viral load is a strong predictor of liver cirrhosis in people chronically infected with hepatitis B virus regardless of $\mathrm{HBe}$ antigen status. J Hepato 2005;42(suppl 2):172.

21 lloeje UH, Yang HI, Su J, et al. Serum hepatitis B virus DNA level predicts the incidence of liver cirrhosis in persons chronically infected with $\mathrm{HBV}$. J Hepatol 2005;42(suppl 2): 180.

22 lloeje UH, Yang HI, Su J, et al. Viral load, not serum ALT is the primary predictor of progression to cirrhosis in persons chronically infected with $\mathrm{HBV}$. Results from a long term prospective study. $J$ Hepatol 2005;42(suppl 2):180.

23 Colonno RJ, Genovesi EV, Medina I, et al. Longterm entecavir treatment results in sustained antiviral efficacy and prolonged life span in the woodchuck model of chronic hepatitis infection. $J$ Infect Dis 2001; 184:1236-45.

24 Liaw YF, Sung JJ, Chow WC, et al. Lamivudine for patients with chronic hepatitis B and advanced liver disease. N Engl J Med 2004;351:1521-31.

25 De Franchis $R$, Meucci $G$, Vecchi $M$, et al. The natural history of asymptomatic hepatitis $B$ surface antigen carriers. Ann Intern Med 1993;118:191-4.

26 Hsu YS, Chien RN, Yeh CT, et al. Long-term outcome after spontaneous $\mathrm{HBeAg}$ seroconversion in patients with chronic hepatitis B. Hepatology 2002;35:1522-7.

27 Chen CJ, Yang HI, Su J, et al. Elevated levels of serum hepatitis $B$ virus DNA is an independent risk factor for hepatocellular carcinoma: A long term follow-up study in Taiwan. J Hepatol 2005;42(suppl 2):35

28 Tang B, Kruger WD, Chen G, et al. Hepatitis B viremia is associated with increased risk of hepatocellular carcinoma in chronic carriers. J Med Virol 2004;72:35-40.

29 Papatheodoridis GV, Manesis E, Hadziyannis SJ. The long-term outcome of interferon-alpha treated and untreated patients with $\mathrm{HBeAg}$-negative chronic hepatitis B. J Hepatol 2001;34:306-13.

30 Brunetto MR, Oliveri F, Coco B, et al. Outcome of anti- $\mathrm{HBe}$ positive chronic hepatitis $B$ in alphainterferon treated and untreated patients: a long term cohort study. J Hepatol 2002;36:263-70.

31 Lau G, Piratvisuth T, Luo KX, et al. Peginterferon alpha 2a (4OKD) (Pegasys) monotherapy and in combination with lamivudine is more effective than lamivudine monotherapy in $\mathrm{HBeAg}$-positive chronic hepatitis $B$. Results from a large multinational study. Hepatology 2004;40(suppl 2):171A.

32 Lai CL, Dienstag J, Schiff E, et al. Prevalence and clinical correlates of YMDD variants during lamivudine therapy for patients with chronic hepatitis B. Clin Infect Dis 2003:36:687-96.

33 Locarnini S, Qi X, Arterburn S, et al. Incidence and predictors of emergence of adefovir resistant HBV during four years of adefovir dipivoxil (ADV) therapy for patients with chronic hepatitis B. $J$ Hepatol 2005:42(suppl 2):17.

34 Chang GG, Gish R, de Man R, et al. Entecavir is superior to lamivudine for the treatment of $\mathrm{HBeAg}$ (+) chronic hepatitis B: Results of phase III study ETV-022 in nucleoside naïve patients. Hepatology 2004:40(suppl 1):193.

35 van Bommel F, Wunsche T, Mauss S, et al. Comparison of adefovir and tenofovir in the treatment of lamivudine-resistant hepatitis $B$ virus infection. Hepatology 2004;40:1421-5.

Southern England. The analyses were based on discharge and death certificate statistics. One year after admittance, the mortality rate was $34 \%$, and remained so during the entire 30 year observation period. One year after admittance, the standardised mortality rate was 16.3 times that of the general population. These findings were robust to different analytical strategies. The disappointing results during the 30 year period were obtained both for the total group of 8192 patient admissions as well as for the diagnostic subgroups individually. The data show how deadly liver cirrhosis has been and continues to be.

Why does cirrhosis mortality remain unaffected despite our impression that it is decreasing? We expect decreasing mortality due to the use of many new interventions. Interventions such as liver transplantation, ${ }^{2}$ endoscopic treatment for bleeding varices, ${ }^{34}$ prevention of bleeding and rebleeding from varices with beta blockers, ${ }^{3}{ }^{4}$ antiviral drugs for

sis mortality during the years 1968 to 1999 (see page 1615). This must be provoking, disappointing, and sobering reading for many.

Roberts and colleagues ${ }^{1}$ based their findings on 8192 patients admitted to hospitals in the Oxford region of 
hepatitis $\mathrm{B}$ or $\mathrm{C}^{56}$ and antibiotics for preventing and treating complications to cirrhosis, ${ }^{3-9}$ have all been introduced during the study period.

Three major causes may explain the contrast between the finding of no significant change in mortality on the one hand and our expectation of decreasing mortality on the other: erroneous findings, misguided perceptions about the effectiveness of interventions, or incorrect implementation of interventions.

\section{ERRONEOUS FINDINGS}

A change in "patient mix" over time is a plausible possibility for erroneous findings. Nurses and physicians feel that the people they care for and treat are becoming more severely ill. The workload connected with the individual patient is rising, and so does the number of hospital admissions. Outpatient clinics are growing at a rate of approximately $2 \%$ per year. Part of this growth could be due to handling less diseased patients as outpatients. Accordingly, more severely diseased patients are admitted to hospital wards. This would raise mortality. But improved treatments keep the mortality at a constant level. Therefore, no net change in mortality is observed.

The patient mix could be influenced by diagnostic drift. Thirty years ago the diagnoses of "non-alcoholic steatohepatits" and "non-alcoholic fibrosis and cirrhosis" were rarely used. These diagnoses have become trendy over the years. ${ }^{10}$ This may have moved the less severely diseased patients from the alcoholic cirrhosis group to the "new" diagnostic entities. Studies on the "new" non-alcoholic liver diagnoses rarely exclude alcohol problems by adequate means, ${ }^{11-14}$ so why should clinical practice?

Roberts and colleagues ${ }^{1}$ may have chosen the "wrong" sampling unit? During the past decades population based liver cirrhosis mortality rates have increased significantly in England, in contrast with other EU countries where it is falling. ${ }^{15}$ The increase in alcohol consumption may lead to increased mortality rates. This could impact on the patient mix and the findings. However, the findings of Roberts and colleagues ${ }^{1}$ concur with data from other regions of England $^{16}$ and from Denmark. ${ }^{17}$

Roberts and colleagues ${ }^{1}$ used administrative discharge data for their identification of cases. Diagnostic discharge data are not entirely accurate and liver cirrhosis may have been misclassified in $5-10 \%$ of cases, according to the Danish experience. ${ }^{18} \quad$ Such misclassification however would not explain the lack of improvement in liver cirrhosis mortality unless one could point to a systematic change connecting misclassification over time with changed mortality.

We must consider the possibility of a type II error-no improvement was detected although it actually happened. Nobody can exclude this possibility. The type II error is in fact substantial. Mortality during the period 1994 to 1999 had an odds ratio of 0.90 (95\% confidence interval (CI) 0.74-1.09) compared with mortality in the period 1968 1973 (table 4 in Roberts and colleagues $\left.^{1}\right)$. This corresponds to the finding that mortality may have decreased by $26 \%$ or increased by $9 \%$. Only much larger studies, preferably including national or international data, may resolve this issue.

\section{LACK OF BENEFICIAL EFFECT OF INTERVENTIONS CONSIDERED TO BE EFFECTIVE}

The second major cause for the contrast between no significant improvement in mortality on the one hand and our expectation of improvements in mortality due to new methods for prevention, diagnosis, treatment, and care on the other is misguided expectations. Could it be that there has in reality been no improvement in mortality during the last 30 years?

We have no randomised clinical trials demonstrating that cirrhosis mortality can be significantly decreased by liver transplantation. However, we have cohort studies and matched controlled and simulated studies suggesting that this may be so, but these analyses only point to the fact that Child class C patients may have a gain in survival. ${ }^{2}{ }^{19}$ Furthermore, less than 25 Child class C patients undergo liver transplanted per year in the Oxford region. This number could not influence the statistics for a whole region.

Endoscopic banding in the primary prevention of variceal bleeding may prevent bleeding but endoscopic banding does not seem to have significant effects on mortality. ${ }^{20}$ Beta blockers are also recommended for primary prevention $^{3}$ but we have been unable to demonstrate any significant effect of beta blockers on mortality in high quality trials (Chen W et al, unpublished observations).

Terlipressin and endoscopic interventions may significantly decrease mortality in patients with acute variceal bleeding. But we still lack information on the influence of these interventions on long term mortality. ${ }^{321} 22$

Prevention of rebleeding from varices with beta blockers, endoscopic measures, or transjugular intrahepatic portosystemic stent shunt (TIPS) may have significant effects on mortality but the results are modest. ${ }^{32-25}$ TIPS may remove more ascites but cause more hepatic encephalopathy and does not seem to have significant effects on mortality. ${ }^{26}$

Much marketing has gone into interventions for chronic hepatitis $\mathrm{B}$ and chronic hepatitis $\mathrm{C}$. We do not have any firm knowledge on how interferons affect mortality in patients with chronic hepatitis B. ${ }^{27}$ Lamivudine seems to affect the clinical course in patients with chronic hepatitis B and advanced liver disease. ${ }^{28}$ However, we have no convincing evidence showing a significant effect of lamivudine ${ }^{28}$ on the mortality of chronic hepatitis B patients. The situation for patients with chronic hepatitis C is not much better. Combination therapy with interferon and ribavirin seems to be able to reduce the composite outcome measure of cirrhosis, hepatocellular carcinoma, and death. ${ }^{29}$ Combination therapy significantly reduced the composite outcome measure in all 9991 patients entered into 72 randomised clinial trials (relative risk 0.49 (95\% CI 0.25-0.96; number needed to treat to benefit one patient 419 (95\% CI 290-4523)) but not in naive, relapsers, or non-responders individually. ${ }^{29}$ Furthermore, we found no significant effect of combination therapy on mortality as an isolated outcome..$^{29}$

Antibiotics are recommended for preventing and treating complications of cirrhosis. ${ }^{3-9}$ Although antibiotics seem to reduce short term mortality we urgently need data on their influence on long term mortality.

\section{INCORRECT IMPLEMENTATION}

If the explanation that the interventions do not work is unpalatable, then try this: the interventions worked only a little in clinical research but were incorrectly applied in clinical practice.

We recently assessed the degree of concurrence between research evidence and clinical practice in Denmark. ${ }^{30}{ }^{31} \mathrm{We}$ evaluated the agreement between research evidence in Cochrane HepatoBiliary Group systematic reviews ${ }^{32}$ and reported on the use of clinical interventions for typical patients presenting no contraindications. The Cochrane Hepato-Biliary Group had completed 28 systematic reviews on 36 interventions that were available in Denmark in 2002. Based on the reviews, three interventions with significant beneficial effects on clinical outcomes were classified as "evidence based" (n-acetylcysteine for paracetamol overdose, ${ }^{33}$ terlipressin for bleeding oesophageal varices, $^{21}$ and antibiotics for patients with cirrhosis and gastrointestinal 
bleeding $^{7}$ ) whereas 19 were classified as "possibly evidence based" and 14 as "not evidence based". Questionnaires on reported use and perceived intervention effects were mailed to senior physicians practising in Danish hospitals and being responsible for the treatment of liver patients. The proportion of physicians who reported that they never used the three evidence based interventions varied considerably $(2 \%, 57 \%$, and $62 \%$, respectively). The perceived intervention effect, duration of clinical experience, employment as head of department, and university hospital employment were significant predictors of more frequent use of evidence based interventions. Physicians also reported that they used the interventions that were not evidence based more often if they were employed at a university hospital.

So we observed considerable disagreements between research evidence and reported clinical use in Denmark. Although I have no data to prove it, similar or other mechanisms in Oxford could explain incorrect implementation of interventions.

\section{WHAT TO DO NOW?}

As always, when things do not add up more than one thing may be wrong. Could it be a combination of erroneous findings, misguided expectations, and incorrect implementation? The findings in the study of Roberts and colleagues ${ }^{1}$ as well as the increased liver cirrhosis mortality rates in England over time-in contrast with other countries-call for further epidemiological studies in the UK and abroad. In addition to one year mortality, these studies should also examine five and 10 year mortality changes over time.

We may also need to adjust our expectations to the intervention effects. May be the interventions we use are not as effective as we imagine. We therefore urgently need to develop more effective interventions. In addition to finding new interventions for alcoholic liver cirrhosis, for example, ${ }^{34-37}$ we must develop preventive measures for the deadly consequences of the increasing alcohol problems in our societies. We also need to scrutinise the beneficial and harmful effects of the intervention we employ in daily clinical practice. In order to accomplish these developments we must become much better in collaborating. Through collaboration we can conduct much larger randomised clinical trials carried out with much better methodology. ${ }^{38-43}$

We also need more public support for clinical research and possibly less industry involvement. ${ }^{44}{ }^{45}$ Finally, we need full transparency in clinical research with publication of and public access to all protocols, protocol amendments, and clinical data. ${ }^{46}$

Finally, all hospitals and departments should regularly check their clinical practices and clinical guidelines. We need collaboration on getting research into clinical practice. All departments need a team of systematic reviewers who are able to conduct high quality systematic reviews. ${ }^{47}$ Only by being able to do systematic reviews themselves will they become sufficiently critical of meta-analyses and the so-called "systematic reviews" carried out by others. Furthermore, such activities could benefit the systematic reviewers as well as their departments. ${ }^{48}$

Gut 2005;54:1523-1526.

doi: 10.1136/gut.2005.072876

Correspondence to: $\operatorname{Dr} C$ Gluud, Copenhagen Trial Unit, Centre for Clinical Intervention Research, Department 7102, Rigshospitalet, Copenhagen University Hospital, DK 2100 Copenhagen, Denmark; cgluud@ctu.rh.dk

Conflict of interest: None declared.

\section{REFERENCES}

1 Roberts SE, Goldacre MJ, Yeates D. Trends in mortality after hospital admission for liver cirrhosis in an English population from 1968 to 1999. Gut 2005;54:1615-21.

2 Neuberger J. Developments in liver transplantation. Gut 2004;53:759-68.

3 Samonakis DN, Triantos CK, Thalheimer U, et al. Management of portal hypertension. Postgrad Med J 2004:80:634-41.

4 de Franchis R. Evolving consensus in portal hypertension. Report of the Baveno IV consensus workshop on methodology of diagnosis and therapy in portal hypertension. J Hepato 2005;43:167-76.

5 Lok AS, McMahon BJ. Practice Guidelines Committee, American Association for the Study of Liver Diseases (AASLD). Chronic hepatitis B: update of recommendations. Hepatology 2004;39:857-61.

6 Pawlotsky JM, McHutchison JG. Hepatitis C. Development of new drugs and clinical trials: promises and piffalls, Summary of an AASLD hepatitis single topic conference, Chicago, IL, 27 February-1 March 2003. Hepatology 2004;39:554-67.

7 Soares-Weiser K, Brezis M, Tur-Kaspa R, et al. Antibiotic prophylaxis for cirrhotic patients with gastrointestinal bleeding. The Cochrane Database of Systematic Reviews 2002, issue 2. Oxford: Update Software, 2002, art.No CD002907.

8 Soares-Weiser K, Brezis M, Leibovici L. Antibiotics for spontaneous bacterial peritonitis in cirrhotics. The Cochrane Database of Systematic Reviews 2001, issue 3. Oxford: Update Software, 2001, art. No CD002232.

9 Thalheimer U, Triantos CK, Samonakis DN, et al. Infection, coagulation, and variceal bleeding in cirrhosis. Gut 2005;54:556-63.

10 Sass DA, Chang P, Chopra KB. Nonalcoholic fatty liver disease: a clinical review. Dig Dis Sci 2005;50:171-80.

11 Nielsen SD, Gluud C. Physicians' information about alcohol problems at hospitalisation of alcohol misusers. Alcohol Alcohol 1992;27:659-65.

12 Nielsen SD, Storgaard H, Moesgaard F, et al. Prevalence of alcohol problems among adult somatic in-patients of a Copenhagen hospital. Alcohol Alcohol 1994;29:583-90.

13 Storgaard H, Nielsen SD, Gluud C. The validity of the Michigan Alcoholism Screening Test
(MAST)-a review. Alcohol Alcohol 1994;29:493-502.

14 McCusker MT, Basquille J, Khwaja M, et al Hazardous and harmful drinking: a comparison of the AUDIT and CAGE screening questionnaires. QJM 2002;95:591-5.

15 Vass A. Rates of liver cirrhosis rise in England, fall in Europe. BMJ 2001;323:1388.

16 Saunders JB, Walters JR, Davies AP, et al. A 20year prospective study of cirrhosis. BMJ Clin Res Ed 1981;282:263-6.

17 Sørensen HT, Thulstrup AM, Mellemkjar L, et al. Long-term survival and cause-specific mortality in patients with cirrhosis of the liver: a nationwide cohort study in Denmark. J Clin Epidemiol 2003:56:88-93

18 Vestberg K, Thulstrup AM, Sorensen HT, et al. Data quality of administratively collected hospital discharge data for liver cirrhosis epidemiology. J Med Syst 1997;21:11-20.

19 Poynard T, Naveau S, Doffoel M, et al. Evaluation of efficacy of liver transplantation in alcoholic cirrhosis using matched and simulated controls: 5-year survival. Multi-centre group. J Hepatol 1999;30:1130-7.

20 Khuroo MS, Khuroo NS, Farahat KL, et al. Metaanalysis: endoscopic variceal ligation for primary prophylaxis of oesophageal variceal bleeding. Aliment Pharmacol Ther 2005:21:347-61.

21 loannou G, Doust J, Rockey DC. Terlipressin for acute esophageal variceal hemorrhage. The Cochrane Database of Systematic Reviews 2003, issue 1. Oxford: Update Software, 2003, art.No CD002147.

22 D'Amico G, Pagliaro L, Pietrosi G, et al. Emergency sclerotherapy versus medical interventions for bleeding oesophageal varices in cirrhotic patients. The Cochrane Database of Systematic Reviews 2002, Issue 1. Oxford: Update Software, 2002, art.No CD002233.

23 de la Pena J, Brullet E, Sanchez-Hernandez E, et al. Variceal ligation plus nadolol compared with ligation for prophylaxis of variceal rebleeding: a multicenter trial. Hepatology 2005;41:572-8.

24 Saver P, Hansmann J, Richter GM, et al. Endoscopic variceal ligation plus propranolol vs. transjugular intrahepatic portosystemic stent shunt: a long-term randomized trial, Endoscopy 2002;34:690-7.

25 Escorsell A, Banares R, Garcia-Pagan JC, et al. TIPS versus drug therapy in preventing variceal rebleeding in advanced cirrhosis: a randomized controlled trial. Hepatology 2002;35:385-92.

26 Saab S, Nieto JM, Ly D, et al. TIPS versus paracentesis for cirrhotic patients with refractory ascites. The Cochrane Database of Systematic Reviews 2004, issue 3. Oxford: Update Software, 2004, art.No CD004889

27 Colombo M, Donato MF. Prevention of hepatocellular carcinoma. Semin Liver Dis 2005;25:155-61.

28 Liaw YF, Sung JJ, Chow WC, et al. Lamivudine for patients with chronic hepatitis $B$ and advanced liver disease. N Engl J Med 2004;351:1521-31.

29 Brok J, Gluud LL, Gluud C. Ribavirin plus interferon versus interferon for chronic hepatitis $\mathrm{C}$-an updated systematic Cochrane review on 72 randomised clinical trials with 9991 patients. $J$ Hepatol 2005;42(suppl 2):201.

30 Gluud LL, Kürstein P, Kjellberg J, et al. The size of the gap between research evidence and clinical practice: questionnaire survey on treatment of patients with liver disease. 12th Cochrane Colloquium, Ottawa, Canada, 2-6 October 2004: abstract 129).

31 Kürstein P, Gluud LL, Willemann M, et al. Agreement between reported use of interventions for liver diseases and research evidence in Cochrane systematic reviews. J Hepatol 2005 (in press).

32 Gluud C, Als-Nielsen B, D'Amico G, et al. The Cochrane Hepato-Biliary Group. About The Cochrane Collaboration. Collaborative Review Groups (CRGs)) 2005, Issue 2. Oxford: Update Software, 2005, art. No, LIVER.

33 Brok J, Buckley N, Gluud C. Interventions for paracetamol (acetaminophen) overdoses. The Cochrane Database of Systematic Reviews 2002, issue 3. Oxford: Update Software, 2002, art.No CD003328. 
34 Rambaldi A, laquinto G, Gluud C. Anabolicandrogenic steroids for alcoholic liver disease. The Cochrane Database of Systematic Reviews 2003, issue 1. Oxford: Update Software, 2003, art.No CD003045.

35 Rambaldi A, Gluud C. Colchicine for alcoholic and non-alcoholic liver fibrosis and cirrhosis. The Cochrane Database of Systematic Reviews 2005, issue 2. Oxford: Update Software, 2005, art.NoCD002148.

36 Rambaldi A, Gluud C. Propylthiouracil for alcoholic liver disease. The Cochrane Database of Systematic Reviews 2001, issue 4. Oxford: Update Software, 2001, art.No CD002800.

37 Rambaldi A, Gluud C. S-adenosyl-L-methionine

for alcoholic liver diseases. The Cochrane Database of Systematic Reviews 2001, issue 4. Oxford: Update Software, 2001, art.No CD002235

38 Gluud C, Nikolova D. Quality assessment of reports on clinical trials in Journal of Hepatology. J Hepatol 1998;29:321-7.
39 Kiærgard LL, Nikolova D, Gluud C. Randomized clinical trials in hepatologypredictors of quality. Hepatology 1999;30:1134-8.

40 Kjaergard LL, Frederiksen S, Gluud C. Validity of randomized clinical trials in Gastroenterology from 1964-2000. Gastroenterology 2002;122:1157-60

41 Kjaergard LL, Gluud C. Funding, disease area, and internal validity of hepato-biliary randomized clinical trials. Am J Gastroenterol 2002:97:2708-13.

42 Gluud C. Trials and errors in clinical research. Lancet 1999;354:siv59.

43 Kjaergard LL, Villumsen J, Gluud C. Reported methodological quality and discrepancies between large and small randomized trials in meta-analyses. Ann Intern Med 2001;135:982-9

44 Als-Nielsen B, Chen W, Gluud C, et al. Association of funding and conclusions in randomised drug trials. A reflection of treatment effect or adverse events? JAMA 2003;290:921-8.

45 House of Commons Health Committee. The Influence of the Pharmaceutical Industry. Fourth Report of Session 2004-05. 2005. http:// www.publications. parliament.uk/pa/ cm200405/cmselect/cmhealth/42/42.pdf (accessed 23 August 2005)

46 Krleza-Jeric K, Chan A-W, Dickersin K, et al Principles for international registration of protoco information and results from human trials of health related interventions: Ottawa statement (Part 1). BMJ 2005;330:956-8.

47 Higgins JPT, Green S, eds. Cochrane Handbook for Systematic Reviews of Interventions 4.2.4 (updated March 2005), The Cochrane Library, issue 2. Chichester, UK: John Wiley and Sons, Ltd, 2005.

48 Patsopoulos NA, Analatos AA, loannidis JP. Relative citation impact of various study designs in the health sciences. JAMA 2005;293:2362-6.

\section{EDITOR'S QUIZ: GI SNAPSHOT}

\begin{abstract}
Answer
From question on page 1514

Histology confirmed this to be an enterolith adherent to the pouch. Our patient had a follow up evacuating pouchogram which showed stasis in the pouch. Food residue chronically accumulating would act as a nidus for enterolith formation. Morphological abnormalities of the pouch such as twist or mucosal bridge may have a role. We would recommend regular pouch washouts to prevent accumulation of residue and recurrent enterolith formation. Pouch patients may develop transient symptoms of frequency, incontinence, and leakage during pregnancy but these do settle after delivery. Persistent or new symptoms after delivery should be investigated. Plain $x$ rays, computed tomography scan, endoscopy, or examination under anaesthesia help to confirm the diagnosis. Removal of the enterolith can be attempted endoscopically or transanally. Laparotomy may become necessary and access into the pouch may be gained by incising the fundus. These patients require a period of follow up and an evacuating pouchogram to ensure return of good pouch function.
\end{abstract}

doi: $10.1136 /$ gut.2004.062547 